\title{
PERUBAHAN DAN PERKEMBANGAN PANAKAWAN DALAM PEWAYANGAN
}

Nurhadi Siswanto ${ }^{1}$ (nur.ghazy@yahoo.com, Jurusan Kriya Fakultas Seni Rupa Institut Seni Indonesia Yogyakarta)

\begin{abstract}
The Panakawan figure in puppet is the original creativity of Indonesian people. Its existence is recognized as having existed before Islam emerged as the political power in the archipelago (Demak). Since the 12th century the figure of Panakawan has been mentioned in Javanese literature and developed in the walls of the temple's reliefs. Even the presence of Panakawan still exists today, with Semar, Gareng, Petruk and Bagong as the characters. Of course there were many different things between Panakawan pre-Islamic times when compared to the Islamic period. These differences were certainly very interesting to study, so they can show the influence of Islam in the world of Wayang. This paper tries to examine the history, changes and development of Panakawan figures in pre-Islamic times and the Islamic period. Using Alvin Boskoff's theory of change, and the theory of the principle of acculturation to Koentjaraningrat's culture, the author tries to examine various changes, and the development of Panakawan figures in wayang. The results of the study show that changes in the pre-Islamic Panamanian era and the Islamic period were changes due to external factors, namely the domination factor of Islamic teachings in Puppet. The strong influence of Islam has caused many changes to occur in the naming, number, form and function of the Panakawan figures.
\end{abstract}

KeyWord: Punakawan, Puppet, changes and Development

\section{ABSTRAK}

Tokoh Panakawan dalam pewayangan adalah asli kreatifitas manusia Indonesia. Keberadaanya diakui telah ada sebelum Islam muncul sebagai kekuatan politik di bumi Nusantara (Demak). Sejak abad 12 tokoh Panakawan telah disebutkan dalam kesusastraan Jawa dan berkembang pada relief dinding-dingding Candi. Panakawanpun keberadaannya masih eksis sampai saat ini, dengan Semar, Gareng, Petruk dan Bagong sebagai tokohnya. Tentunya banyak hal yang berbeda antara Panakawan masa pra Islam bila dibandingkan dengan masa Islam. Berbagai perbedaan tersebut tentulah sangat menarik untuk dikaji, sehingga bisa menunjukkan pengaruh Islam dalam dunia Wayang. Tulisan ini mencoba mengkaji sejarah, perubahan dan perkembangan tokoh Panakawan pada masa pra Islam dan masa Islam. Menggunakan teori Perubahan Alvin Boskoff, dan teori prinsip akulturasi budaya Koentjaraningrat, penulis mencoba mengkaji berbagai perubahan, dan perkembangan tokoh Panakawan dalam pewayangan. Hasil kajian menunjukkan bahwa perubahan Panakawan masa pra Islam dan masa Islam merupakan perubahan karena faktor eksternal, yaitu faktor dominasi ajaran Islam dalam Pewayangan. Kuatnya pengaruh Islam ini telah menyebabkab banyak terjadi perubahan baik pada penamaan, jumlah, bentuk dan fungsi tokoh Panakawan.

Kata Kunci: Punakawan, Wayang, Peruabahan dan Perkembangan 


\section{PENDAHULUAN}

\section{Latar Belakang Masalah}

Seni nusantara pada umumnya, seni Jawa khususnya, selalu memberikan nilai etis dan estetis yang luar biasa. Orang Jawa telah menciptakan berbagai kreativitasnya yang sangat luar biasa. Berbagai kreativitas orang Jawa tersebut telah menjadi peninggalan yang adiluhung, yang menarik untuk dikaji dan diteliti.

Salah satu bentuk kreatifitas orang Jawa adalah wayang. Kata wayang dapat diartikan gambar atau tiruan manusia yang terbuat dari kulit, kayu, dan sebagainya untuk mempertunjukkan suatau lakon (cerita). Kata wayang berasal dari kata wewayangan atau wayangan yang berarti bayangan. Pertunjukan wayang dapat dipahami sebagai bayangan kehidupan manusia, atau angan-angan manusia tentang kehidupan manusia masa lalu.

Hazeu dalam disertasinya "Bijdrage tot de Kennis van het Javaansche Toneel (1897) menyatakan Indonesia jauh di masa lalu terpengaruh oleh kebudayaan Hindia. Wayang adalah budaya asli Indonesia yang menemukan diri dalam proses yang lama. Kebudayaan Hindu hanyalah sebagai kulitnya, isinya adalah budaya lokal Indonesia (Hazeu, 1872,2).

Salah satu perbedaan menonjol antara cerita wayang kisah mahabarata - Ramayana versi Indonesia dan India adalah keberadaan tokoh "Panakawan". Panakawan adalah tokoh pewayangan yang berperan sebagai pengasuh dan penasehat para kesatria. Panakawan memiliki peranan mengasuh tuannya.

Tokoh Panakawan telah ada jauh sebelum masuknya pengaruh kebudayaan Islam, tetapi pada masa Islam di Jawa tokoh ini banyak dimanfaatkan untuk keperluan dakwah (Sunarto, 2012, 5). Keberadaan Panakawan disebut dalam beberapa karya sastra seperti pada Serat Nawaruci, Serat Gatutkacasraya, Kidung Sudamala, Purwakandha, Pustakarajapurwa, dan Purwacarita.

Wayang di nusantara khususnya di Jawa terus mengalami perubahan dan perkembangan. Wayang pada masa HinduBudha memiliki peran dan fungsi yang tentunya berbeda dengan wayang pada masa sebelumnya. Demikian pula fungsi dan keberadaan wayang pada masa Islam tentunya juga memiliki fungsi dan kharakter yang berbeda dengan wayang pada masa HinduBudha.

Perubahan dan Perkembangan wayang tentunya tidak akan terlepas dari keberadaan politik kekuasaan dan pandangan keyakinan yang berkembang di masyarakat pada waktu itu. Ajaran agama tertentu sangat mungkin berpengaruh besar terhadap perubahan dan perkembangan wayang. Perubahan dan perkembangan wayang terjadi pula pada zaman kerajaan Islam dengan raja dan para wali sebagai kreator. Perubahan tersebut tentunya juga terjadi dalam tokoh dan cerita wayang.

Tulisan ini mencoba untuk mengidentifikasi berbagai perubahan yang terjadi terhadap wayang khusunya perubahan dan perkembangan tokoh Panakawan. Penulis memfokuskan pada perubahan, perkembangan dan perbedaan Panakawan dalam pewayangan pada masa Islam dan pra Islam. Penemuan tentang perbedaan dan perkembangan bentuk serta fungsi tokoh Panakawan pada masa Islam dan masa sebelumnya dapat digunakan sebagai acuan untuk mengetahui seberapa besar pengaruh Islam dalam dunia pewayangan.

\section{METODE PENELITIAN}

\section{Bahan dan Materi}

Profil dan keterangan keberadaan Panakawan masa pra Islam akan dicari dan digali dari berbagai artefak peninggalan yang berkaitan seperti relief candi antara lain Candi Panataran (1320 M), candi Tegowangi (1400 M), candi Sukuh (1437M). Panakawan juga dapat ditemuai dalam kesustraan Jawa antara lain : Kitab Gatutkacasraya karya Empu Panuluh (1188 M), Kitab Nawaruci karya Empu Siwamurti (1500-1619 M). Keberadaan Panakawan pra Islam juga dapat digali pada peninggaan wayang beber yang diyakini sebagai peninggalan kerajaan Majapahit,serta wayang kulit Bali. Termasuk didalamnya buku ataupun artikel yang mengupas hal hal tersebut.

Sementara keberadaan Panakawan masa Islam diperoleh dari berbagai keterangan 
dan peningalan yang ada yang dibuat atau disusun pada masa Islam. Berbagai keterangan tersebut digali dari : Serat Purwakhanda (ditulis atas perintah Hamengku Buwono $\mathrm{V}$ tahun 1847), dan Wayang Purwa gaya Yogyakarta.

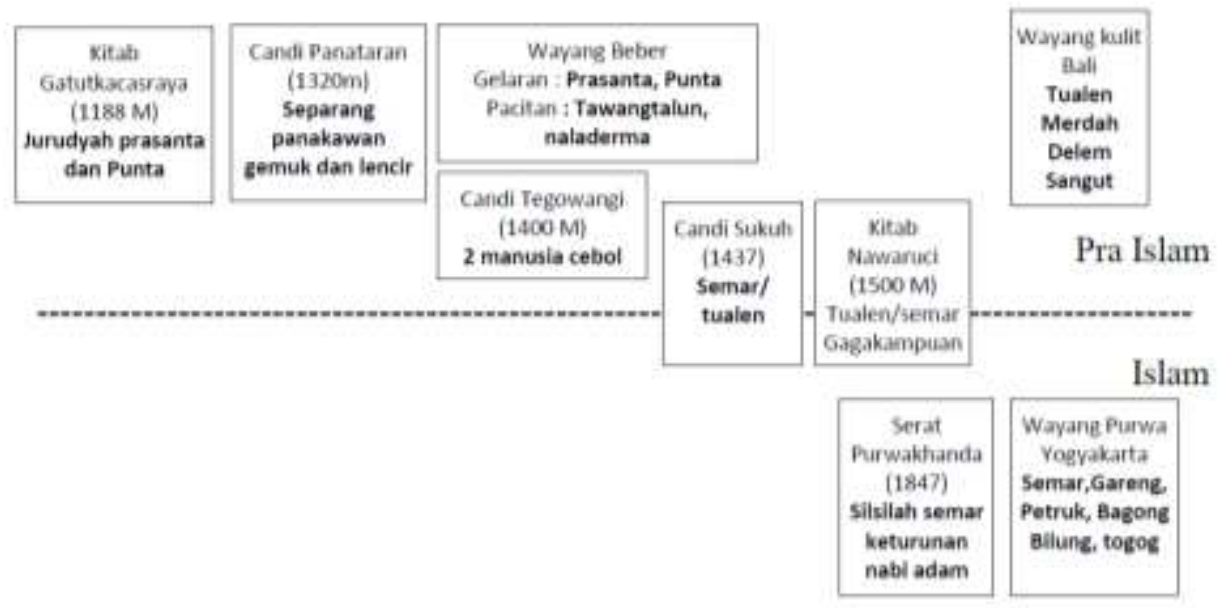

Gambar 1. Ilustrasi keberadaan Panakawan dalam berbagai sumber

\section{PEMBAHASAN}

\section{Pengertian Panakawan}

Panakawan dilihat dari pembentukan kata-nya (etimologi) berasal dari kata pana dan kawan. Kata pana atau yang disebut juga dengan puna memiliki beberapa macam arti, sedangkan kata kawan mempunyai arti kanca (Jawa), teman, atau saudara. Beberapa arti dari kata pana tersebut antara lain: pertama, pana berarti susah sehingga kata panakawan dapat diartikan sebagai teman atau saudara disaat susah. Kemudian pana juga diartikan sebagai terang, berarti panakawan adalah teman atau saudara yang mengajak ke jalan yang terang. Pana juga diartikan sebagai fana yang kemudian mempunyai arti teman atau saudara yang mengajak ke jalan kefanaan, maksudnya adalah berbegaslah untuk memperoleh kebaikan dan tinggalkanlah perkara yang buruk. Selain itu pana juga bermakna paham, panakawan tidak hanya sebagai pengikut majikan, namun mereka juga memahami dengan apa yang sedang menimpa majikannya, seringkali mereka bertindak sebagai penasihat untuk majikannya.

Secara khusus pengertian Panakawan dipahami sebagai tokoh prepat yang sangat dikenal oleh masyarakat yaitu tokoh pewayangan Semar, Gareng, Petruk, dan
Bagong. Panakawan dalam pemahaman yang lebih luas, selain keempat tokoh tersebut terdapat tokoh lain yaitu Togog, Bilung. Panakawan sengaja diwujudkan secara karikaturistik dalam bentuk yang buruk, unik, serta lucu menyiratkan perwatakan dari masing masing tokohnya. Visualisasi tokoh Panakawan dalam dunia pewayangan, memiliki bentuk tubuh yang beraneka ragam, namun secara kesekuruhan memiliki kesamaan fundamental, yaitu sifat kelucuan yang mengundang tawa. Penggambarannya selalu dilebih lebihkan (karikaturistik), sehingga wujudnya menjadi aneh. Bentuk lucu dan tidak proposional yang menjadi ciri utama tokoh ini memiliki arti simbolis yang mendalam.

Serrureir dalam bukunya Wayang Purwa een Wthnologische Studie (1896) menyebutkan bahwa Semar dan anak anaknya (Punakawan) hanya merupakan fantasi orang Jawa yang dimasukan dalam kisah dari negara lain untuk mendramatisir sejarah kepahlawanan nenek moyang orang Jawa. Serrureir bepandangan khusus tentang Semar adalah tiruan dari tokoh Widhusaka dari India, dengan alasan tidak ada tradisi banyolan di tanah Jawa pada waktu itu, Tokoh Wiidhusaka dari india ini sama dengan 'Hanjworst' 
(pelawak) dari Germania atau sama dengan polichinel atau 'Harlekijhj' (badut) dari Itali. Namun pendapat ini dibantah oleh Hazeu (1897) yang menyebutkan bahwa dalil-dalil Serrureir tidak dapat dipertahankan, menurutnya pertunjukan wayang di Jawa yang dikenal dengan Wayang adalah diciptakan orang Indonesia, dan banyol atau lawak telah sering disebut dalam tulisan tulisan kuno (Sri Mulyono, 1989, 24-26).

Kharakteristik Panakawan dapat mewakili profil manusia secara umum. Panakawan merupakan tokoh multi-peran yang dapat menjadi penasehat, penghibur, kritikus, penyampai kebenaran, kebajikan, dan penganjur keutamaan. Tokoh Panakawan menjadikan orang dapat mengambil hikmah bahkan dengan tanpa terasa telah menertawakan diri sendiri (Ardian Kresna, 2012,17).

\section{Sejarah dan Perkembangan Panakawan}

Berikut ini perkembangan wayang khususnya punakawan dari masa pra-Islam sampai masa Islam.

\section{a. Panakawan dalam Sumber Tertulis}

Keberadaan tokoh Panakawan diyakini telah ada pada abad XI pada masa kerajaan Kediri dalam karya sastra pewayangan. Tokoh Panakawan ada dalam kitab Gatutkacasraya hasil karya Empu Panuluh pada tahun 1110 Jawa atau 1188 Masehi. Poerbatjaraka menjelaskan bahwa dalam kitab Gatutkacasraya pertama kali yang menceritakan satria didampingi oleh Panakawan (Poerbatjaraka, 1957, 32).

Kemudian pada abad XV-XVI sebagai masa transisi antara kekuasaan Hindu- Budha ke Islam, tokoh Panakawan juga diceritakan dalam kitab Nawaruci hasil karya Empu Siwamurti. Tokoh yang diceritakan dalam kitab itu bernama Tualen, sebagai pengiring Bima. la bersama punakawan lainnya yang bernama Gagakampuan. Bila dicermati, jarang dijumpai punakawan dalam menjalankan tugasnya sendirian. Umumnya tokoh punakawan selalu berpasangan. Pada kitab ini nama Semar mulai muncul. Ada dua Punakawan yang mengiringi Bima, yaitu Tualen dan Gagakampuan. Tokoh Punakawan bernama Tualen, sering pula disebut Semar, sedangkan Gagakampuan belum diketahui nama lainnya.

Panakawan juga terdapat di dalam Kidung Sudamala. Menurut Ki Padmopuspita Y, di dalam Kidung Sudamala terdapat 36 bait yang menyinggung mengenai tokoh Panakawan. Ketiga puluh enam bait itu tersebar pada: Syair I pada bait 99, dan 101; Syair II terdapat pada bait: 13, 16, dan 42; Syair III terdapat pada bait: $12,14,15,19,20$, dan 21; Syair IV terdapat pada bait: 30, 33, 36, $37,39,40,41,42,43,44,45,46,65,66,67$, $88,89,91,92,95,165,166,167,174$, dan 175.

Panakawan yang ada di dalam baitbait Kidung Sudamala ini telah ada dua bagian yaitu Panakawan golongan tengen yang mengiringi para satria pandawa yang bernama Semar. Juga terdapat Panakawan golongan kiwa yang mengikuti raksasa sebagai musuh pandawa yang bernama Dilem dan Sangut.

Sumber tertulis lainnya yang membahas mengenai punakawan serat Purwakanda, dan Serat Purwacarita. Serat Purwakanda yang sering disebut kitab babone wayang, ditulis berdasarkan perintah dari Sri Sultan Hamengku Buwana $\vee$ pada hari Jumat kliwon, 19 Dulkaidah, tahun Dal 1755, pukul 15.00, musim karo wuku Medhangkungan, lambang Langkir atau 29 Oktober 1847. Dapat dipastikan Serat Purwakhanda disusun pada masa Islam.

Pada Serat Purwakanda terdapat dalam pupuh Asmarandhana di bait 7, 8, 9, 10, 11, 12, 13, 14, dan 15. Dikisahkan di dalam serat ini Semar hanya ditemani oleh seorang yang bernama Dublajaya. Berkaitan dengan tokoh itu diceritakan ketika Palasara kawin dengan Dewi Lara Amis, Semar juga ingin dikawinkan. Oleh Dewi Lara Amis dikawinkan dengan anak seorang mantri bumi di Negeri Wirata. Istri Semar tersebut memiliki adik lakilaki yang bernama Dublajaya yang seterusnya menjadi kawan Semar. Dublajaya dalam pedalangan Yogyakarta merupakan nama lain dari Tokoh Petruk.

\section{b. Punakawan pada Relief Candi}

Keberadaan tokoh Panakawan selain terdapat dalam karya sastra juga terdapat dalam artefak peninggalan. Terdapat tiga candi 
yang memiliki adegan mengenai tokoh Panakawan, yaitu: candi Panataran candi Tegawangi, dan candi Sukuh.

Pada Candi Panataran, terdapat relief dari cerita wayang Ramayana. Terdapat dua sosok Panakawan. Sepasang tokoh Panakawan tersebut bertubuh subur dan kecil. Salah satu dari sepasang punakawan tersebut ada yang ditampilkan dengan tubuh besar atau gendut dengan mulut berkumis, hidung pèsèkan, bathuk nonong, mata bulat melotot, Badannya ngropoh besar dengan perut bulat. Sosok Panakawan tersebut digambarkan menderita penyakit gondok dan ditelinganya memakai anting-anting bulat. Panakawan tersebut mengenakan kain yang diikat dengan sabuk dan posisi muka ditampilkan dengan langan, memakai perhiasan kalung pada lehernya dan gelang dikedua tangannya, kepala dihias dengan zamang yang mengikat kepalanya, dengan rambut diikat pada bagian atas kepala.
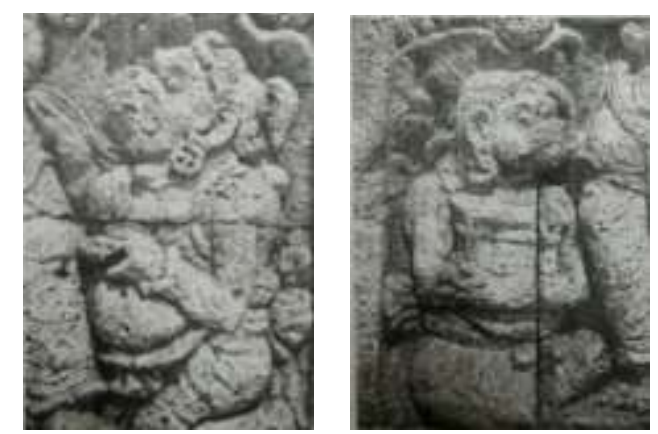

Gambar 2. Relief pada candi Panataran yang diyakini sebagai sosok Panakawan

Sosok Panakawan yang kedua bertubuh lecir (kurus), mulut ciut berkumis, hidungnya pèsèkan, mata pecicilan. Tokoh Panakawan ini mengenakan kain panjang yang diikat dengan sabuk pada bagian perutnya, mengenakan ikat kepala dengan rambutnya diikat pada bagian atas dan memakai anting ring ditelinganya. Tubuh ngropoh kecil tanpa perhiasan atau polos, dan lehernya ditampilkan panjang dengan Posisi muka digambarkan langak. Panakawan ini ditampilkan tidak proporsional dengan gaya karikaturistik dan membawa sebuah sebuah kotak yang terbuka pada bagian atasnya dipegang erat menempel di dadanya.

Candi yang kedua yang terdapat relief yang dipercaya sebagai sosok Panakawan adalah candi Tegowangi. Pada salah satu panel dikisahkan tentang keberhasilan Sudamala meruwat Sri Huma kemudian diberi tugas untuk datang ke Prangalas demi meruwat Tambapetra seorang pendeta yang buta. Kisah selanjutnya Sudamala diambil menantu oleh pendeta tersebut. Kehadiran Sakula pun disambut baik oleh Tambapetra dan diambil menantu. Tambapetra didampingi tokoh Panakawan. Sosok Panakawan pada candi Tegowangi ini tampilannya tidak terlalu jelas, namun nampak dua sosok manusia yang bertubuh kecil (cebol). Gambaran Panakawan tersebut berbadan gempal dengan rambut kuncir atas, mulutnya lebar dan memakai anting ditelinganya, serta mengenakan kain pada bagian bawahnya.

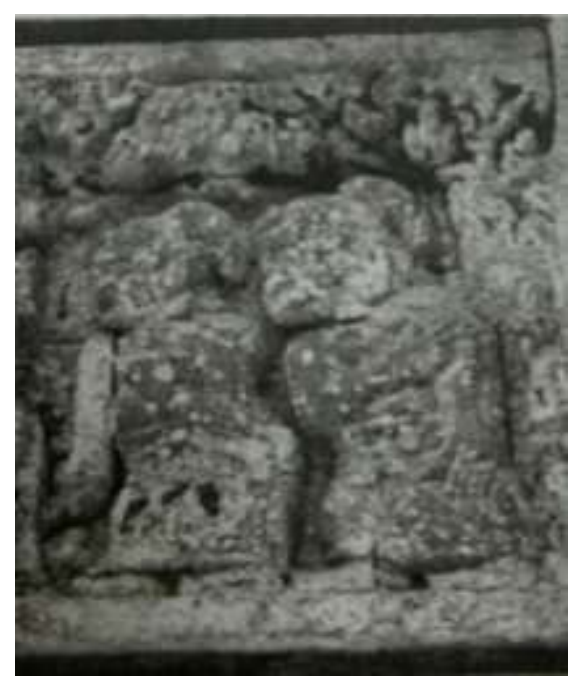

Gambar 3. Relief sosok panakawanpada relief candi Tegowangi

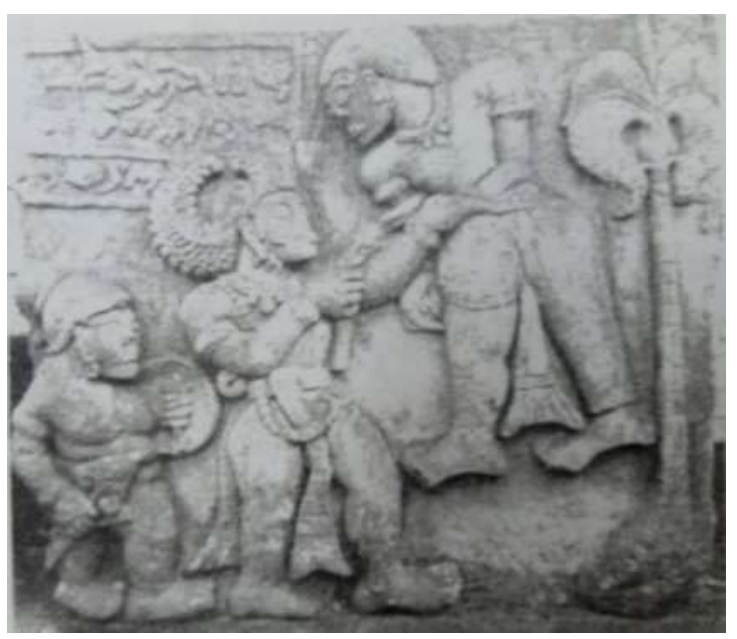

Gambar 4. Relief yang diyakini sebagai sosok Panakawan pada candi Sukuh 
Candi yang ketiga adalah candi Sukuh. Didalam candi ini terdapat relief yang mengambil cerita dari Kidung Sudamala. Pada salah satu relief candi diceritakan Tambapetra yang diikuti oleh Panakawan. Adegan tersebut menceritakan Sudamala yang akan dijodohkan dengan anak sang pendeta. Pada saat itu punakawan (Semar) juga memiliki keinginan untuk memiliki seorang istri, sehingga ia diberikan gadis bernama Ni Towok.

Tokoh Semar pada relief candi Sukuh digambarkan dalam bentuk yang mirip Tualen (Panakawan wayang Bali) dengan gambaran penampilan yang mengenakan rambut yang diikat pada bagian atas dan bagian muka dan belakang rambutnya terurai. Semar pada relief tersebut juga mengenakan gelang di lengan dan ditangannya dengan posisi jari-jari ngepel. Badan Semar digambarkan dengan buah dada yang besar dan mengenakan kain pada bagian bawahnya.

\section{c. Punakawan dalam Wayang Beber}

Wayang beber berarti wayang yang dibeber atau digelar, dibuat di atas lembaran kertas Jawa atau kertas panaraga, dimainkan dengan cara kain yang bergambar adegan cerita wayang dibuka atau direntangkan atau dibeber oleh dalang. Tokoh-tokoh pada wayang beber tidak berdiri sendiri-sendiri, melainkan dalam satu lembar kertas atau kain berisi satu lukisan adegan atau jagong. Gambar pepohonan digunakan untuk membatasi adanya beberapa adegan dalam satu lembar. Semakin banyak adegan dalam satu lembar kertas atau kain maka akan semakin banyak pula gambar pohon yang dibuat.

Tokoh Panakawan dapat dijumpai dalam adegan wayang beber yang berasal dari Desa Gelaran, Gunungkidul dengan cerita Remeng Mangunjaya. Terdapat sepasang tokoh Panakawan yang bernama Prasanta dan Punta. Prasanta berpenampilan gemuk dan tidak proporsional. Sosok Prasanta digambarkan dengan bentuk badan ngropoh, perut bundar, dan bulat besar. Muka Prasanta digambarkan dengan hidung pèsèkan, mata kelipan, sepasang bibir yang tebal dengan satu gigi tampak, dagu besar berkumis. Pada dahi tergambar sinom dengan rambut bagian atas dan belakang diikat dan sebagian lagi terurai. Prasanta menyandang keris ladrang. tangan dan kaki polos tanpa mengenakan perhiasan. Menggunakan atribut kalung kain dan antinganting.

Tokoh Panakawan yang lain adalah Punta berbadan lebih kecil Prasanta. la juga mempunyai wujud yang tidak lazim layaknya Panakawan lainnya. Punta bertubuh ngropoh dengan perut bundar kecil, kepala gundul dengan ikat kepala berbentuk tali pada kepala bagian belakang. Hidung bulat dan besar, mata kelipan sepasang, tampilan mulut gusèn dengan beberapa gigi. Mengenakan sumping sekuntum bunga mekar.
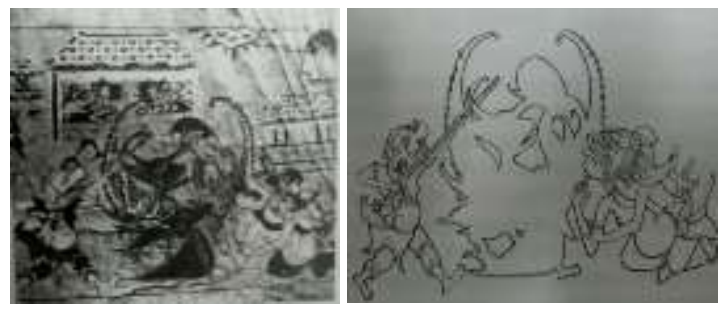

Gambar 5. Sosok Panakawan Perasanta dan Punta pada wayang beber yang ditemukan di Gunungkidul

Wayang beber yang berasal dari Karangtalun, Pacitan, Jawa Timur juga mempunyai sepasang tokoh Panakawan yang bernama Tawangtalun dan Naladerma. Tawangtalun mirip dengan Panakawan dalam wayang beber Gunungkidul yaitu Punta. Tokoh Panakawan ini digambarkan memiliki perut bundar polos, dengan kepala botak, hidung bulat lonjong, mata kelipan sepasang, mulut gusèn. Memakai sumping bunga yang sedang mekar serta daunnya.

Naladerma bertubuh pendek dan gemuk. Badan polos dengan perut bulat besar. Kepala memiliki rambut ditali pada bagian atas dan bagian belakang terurai bebas. Didahinya terdapat sinom, mempunyai mata sepasang kiyipan, berhidung pèsèkan, mulutnya mesem dengan gigi satu dan berdagu besar. Memakai sumping sekuntum bunga mekar dan dedaunan serta memakai subang atau giwang. Naladerma memiliki kemiripan dengan tokoh Prasanta, Tualen, atau Semar dalam relief candi Sukuh. 


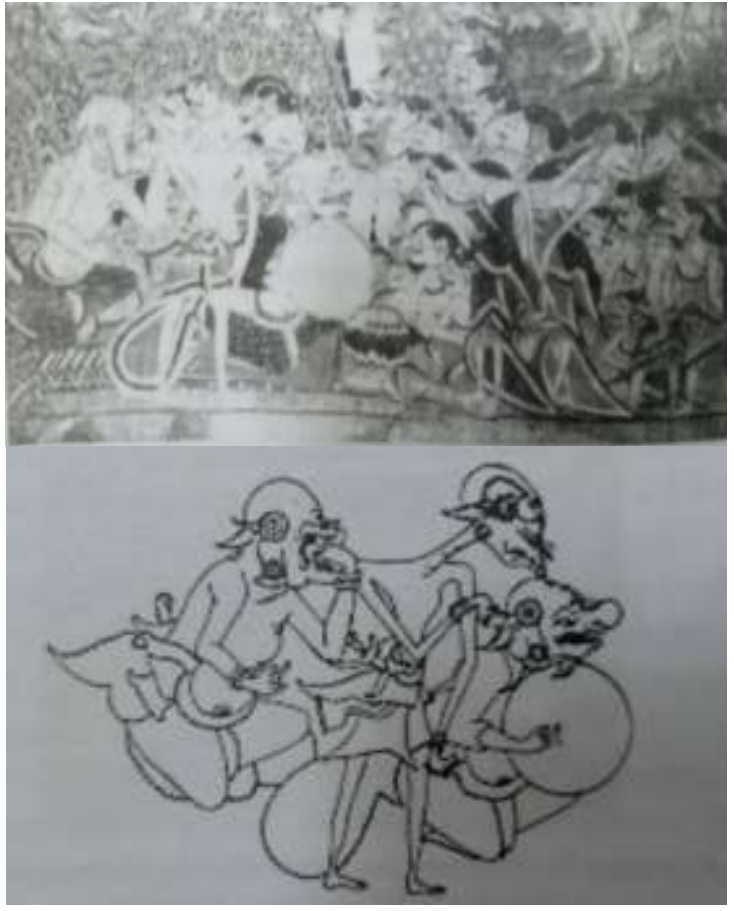

Gambar 6. Tokoh Panakawan Tawangtalun dan Naladerma (prasanta/tualen/semar) Pada wayang beber Karangtalun, Pacitan

\section{d. Panakawan Wayang Kulit Bali}

Bentuk tokoh Panakawan dalam wayang purwa Bali tidak proporsional, ditampilkan dengan gaya karikaturistik, unik dan lucu. Panakawan di Bali disebut juga parkan atau park. Kata park memiliki pengertian dekat, yang dimaksudkan adalah abdi yang dekat, taat, patuh terhadap raja atau tokoh yang menjadi tuannya. Sifat penurut, jujur, dan setia serta tabah merupakan ciri dari tokoh parkan.

Panakawan dalam wayang Bali dibedakan menjadi dua kelompok, yaitu: kelompok tengen dan kelompok kiwa. Tokoh Panakawan tengen terdiri dari sepasang, yaitu: Tualen dan Merdah. Tokoh Tualen diwujudkan dengan muka berhidung kecil, bermata kupit, dengan mulut mèsem tergambar giginya tinggal satu. Dagu dibuat terpisah dan disambung dengan gegel, kemudian diberi tali, rambut diikat pada bagian atas, selebihnya terurai. Jenis hiasan kepala ini di Bali disebut gelung manusia atau udheng-udhengan, memakai sumping dari bunga dan dedaunan, badannya polos tanpa hiasan bertubuh besar dengan perut bundar dengan tangan memakai gelang. Tokoh ini tampak pendek dan dhepah, namun harmoni.

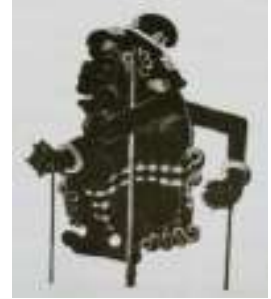

Tualen

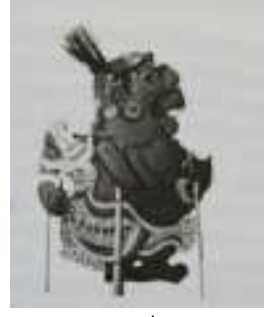

Delem

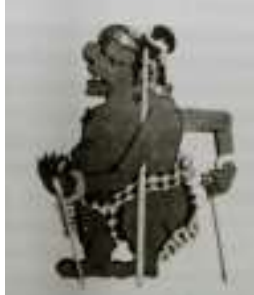

Merdah

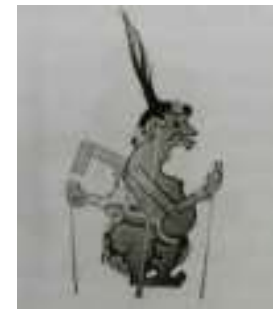

Sangut
Gambar 7 Panakawan Wayang Bali

Tokoh Merdah atau Wredah digambarkan berhidung besar dengan mata kupit dan bermulut mingkem. Rambut diikat pada bagian atas, lainnya terurai. Badan gemuk ngropoh perutnya bulat tidak begitu besar, tangannya mengenakan gelang. Kaki polos dengan memakai kain panjang untuk sabuk serta digunakan untuk menutup aurat dengan ujung-ujungnya ada di kiri dan kanan kaki. Kain panjang yang dipakai tokoh punakawan ini bermotif polèng khas Bali hitam putih. Ukuran tokoh ini lebih kecil dibandingkan dengan pasangannya Tualen.

Tokoh Panakawan kiri jumlahnya juga sepasang, yaitu: Delem (Dilem) atau Melem dan Sangut. Panakawan ini memiliki tabiat suka merendahkan orang lain, iri hati, dan jahat ini menjadi pengikut atau abdi dari tokoh yang berwatak angkara murka, jahat, dan sombong. Tokoh Delem (Melem) ditampilkan dengan bentuk yang tidak proporsional, berhidung kecil, mata bulat mecicil, mulut mecucu, dengan mulut tergambar gigi yang tinggal satu, dagu besar dan dapat digerakgerakkan. Delem memakai sumping bunga dengan giwang yang berukuran besar. Kepala memakai topi udheng-udhengan dan disambung dengan rambut kuda pada bagian atasnya. Leher dibuat mekar yang menggambarkan berpenyakit gondhok. Pada bagian kepala dibuat sambungan untuk menunjukkan leher yang mekar itu agar lebih jelas. Badannya ngropoh dengan perut bulat 
dan bodong, dengan menyandang keris, tangannya mengenakan gelang. Pada bagian bawahnya mengenakan kain bermotif. Ukurannya hampir sama besar dan lebih ramping dengan Tualen.

Tokoh Sangut diwujudkan dengan hidung bulat kecil, mata bulat mecicil, mulut agak maju (nyonyor/monyong) dengan gigi satu. Dagu dibuat sambungan agar dapat digerak-gerakkan, memakai topi udhengudhengan dengan disambung rambut kuda pada bagian atasnya, memakai sumping bunga dan anting-anting di telinganya. Posisi muka longok, lehernya panjang laksana angsa dengan tubuh kecil dengan perut bulat dan bodong. Tangannya memakai gelang dan menyandang keris Bali.

\section{e. Panakawan wayang Purwa Gaya Yogyakarta}

Wayang purwa merupakan salah satu jenis wayang yang terbuat dari kulit binatang. Terdapat banyak ragam jenis wayang purwa, namun sebagai acuan, dalam penelitian ini diambil tokoh panakawan wayang kulit keraton Yogyakarta. Tokoh Panakawan Yogyakarta terdiri dari Panakawan golongan tengen (Semar, Gareng, Petruk, dan Bagong), juga terdapat Panakawan Galongan kiwa (Togog dan Bilung)

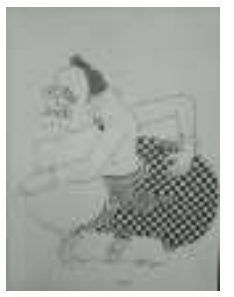

Semar

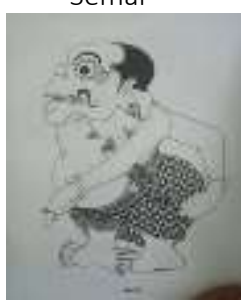

Bagong

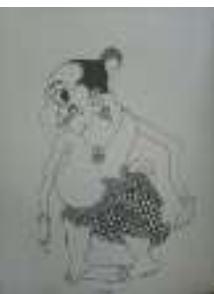

Gareng

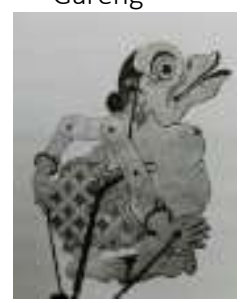

Togog

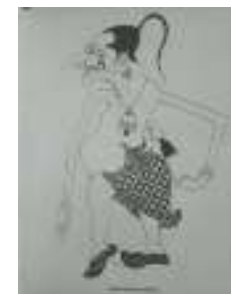

Petruk

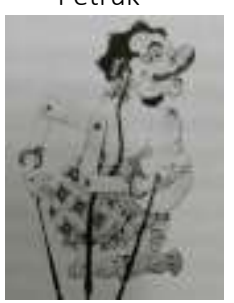

Bilung
Gambar 8. Panakawan Yogyakarta

\section{i. Semar}

Semar memiliki kuncung, hidung sunthi, membulat kecil, tapi tidak pesek. Badan ngropoh dengan susu bulat, mata rembesan, mulut cablek atau nyablek Posisinya agak terbuka dengan dagu menjorok ke depan atau nyadhuk, dan tangan kiri nuding, tangan kanan megar. Semar menggunakan perhiasan Giwang lombok abang, gelang gligen, sabuk dawala, pocong dagelan dengan motif poleng.

\section{ii. Nala Gareng}

Gareng sering dipahami sebagai anak tertua dari Semar. Gareng memiliki: rambut yang dikucir, mata keran atau juling, hidung nerong glatik (mirip terong kecil atau terong glatik). Mulut mesem dengan dagu cupet. Badan ngropoh, berukuran kecil dengan perut ngendil, bahunya brojol. Tangan kiri tekle, tangan kanan ceko, Jari-jari kiri ngepel, Jari-jari kanan nuding. kaki kanan pincang atau gejig. Gareng menggunakan atribut Kalung gobog (bandul yang dibuat dari uang logam kuno yang tengahnya berlubang segi empat), sabuk dawala artinya tali atau pengikat. Dawala ditampilkan dengan sungging tlancapan kombinasi warna biru dan merah gradasi.

\section{iii. Petruk}

Tokoh Petruk memiliki: rambut yang dikucir dan dikelabang, mata dhelen hidung mare ula (bentuknya seperti pare ula). Mulut mesem ditampilkan pada bagian ujung mulut tampak lekukan ke atas, bibir bawah melipat ke bawah dengan dagu goleng. Antara bibir atas dan bawah ada gigi berwarna putih. Tubuh Petruk digambarkan jangkung (gagah), perut ngendhil dan pusarnya bodhong. Bentuk tangan, kaki, dan bagian yang lain juga dipanjang-panjangkan, tangan kiri ngepel, tangan kanan nudhing, Kaki kanan jinjid dan bersepatu. Tokoh Petruk menggunakan kalung gentha, menyandhang pethel Menggunakan Dawala sutra, gelang dhagelan atau gelang binggel dengan ikal kecil di atasnya.

iv. Bagong

Bagong memiliki unsur-unsur: tubuh ngropoh, mata mleleng atau pleleng, hidung sunthi atau nemlik, mulut dobleh atau domble atau dower, bibir bawah yang tebal dan terlipat ke bawah dengan dagu goleng bersusun. Pada bagian tengah antara bibir atas dan bawah terdapat sebuah gigi. Bagong menggunakan kalung gobog, Gelang dhagelan. 


\section{v. Togog}

Togog merupakan tokoh Panakawan kiri yang cukup dikenal dengan abdi raja sabrang. Tokoh Panakawan ini muncul selalu dalam rangka mengingatkan tuannya agar jangan melawan ksatria, tetapi karena tuannya tidak mau mendengar nasehatnya, maka dijlomprongaké agar tuannya mati sekalian. Tokoh ini memiliki atribut: Tubuh ngropoh, hidung pèsèkan, mata plolon, bentuk dari mata plolon ini merupakan modifikasi dari mata plelengan ageng, mulut ngembang kecubung dengan bibir tebal bagian atas, dan bawah menjorok ke muka. Bibir sangat tebal, sehingga mengalahkan dagu lipat yang ukurannya cukup kecil.. Togog menggunakan Gelung kondhé atau gondhèl, yaitu bentuk penataan rambut dengan diikat dibagian belakang kepala, yang umumnya dilakukan oleh wanita Jawa pada masa lampau. Juga menggunakan Luwuk, sejenis pisau diselipkan di pinggang.

\section{vi. Bilung}

Tokoh ini merupakan Panakawan golongan kiri pasangan Togog. Tokoh ini memiliki unsur utama atau atribut kuat, sebagai berikut: Tubuh ngropoh, perut bundar nampak seperti kekenyangan, tubuh borokan (penyakit kurap yang ada di kepala, sehingga membuat rambut gimbal, tokoh yang mempunyai penyakit itu akan selalu menggaruk-garuk kepala). Hidung pèsèkan, (ukurannya sangat kecil), mata pecicilan, (jelalatan, pendirangan, melihat kesana kemari dengan tidak sopan). Mulut anjebèr, bibir atas membulat dan mekar ke atas, sedangkan bibir bawahnya ditandai dengan bibir terlipat dengan dagu golèng bertingkat, mulut bergigi grontolan berjumlah dua biji saja.

Bilung mengenakan Luwuk, mirip pisau dapur dengan sarung pisaunya terbuat dari kayu. Tangan nuding jari telunjuk dan penunggul tampak tegak, kemudian kedua jarijari lainnya dilipat dengan ibu jari diletakkan dekat dengan jari telunjuk. Tangan megar, yaitu posisi telapak tangan dengan ibu jari berada di atas, dilanjutkan dengan empat jarijari berada di bawahnya. Gelang gligèn, bentuk gelang gligèn seperti binggèl namun ditambah dengan bentuk ikal kecil di atasnya dan menggunakan sabuk dawala (pengikat kain).

\section{Pengaruh Islam dalam perkembangan tokoh Panakawan}

Meneliti dan mengamati keberadaan wayang khususnya tokoh Panakawan pada masa lampau (pra Islam) bukanlah hal yang mudah. Sulit untuk bisa mendapatkan gambaran yang komprehensif tentang hal tersebut. Namun demikian eksistensi wayang, termasuk tokoh Panakawan, keberadaan masih bisa dilacak dari berbagai artefak yang ada. Keberadaan tokoh Panakawan selain dapat dijumpai dalam sumber tertulis, dalam berbagai serat dan kidung, juga dapat dijumpai keberadaannya pada relief-relief candi.

Baik dalam karya sastra maupun relief candi keberadaan tokoh Panakawan nampak jelas telah ada. Jumlah tokoh Panakawan pada masa ini sangat terbatas antara satu atau dua tokoh, peranannya sebagai pelengkap cerita dengan posisi sebagai abdi kaum bangsawan. Slamet Muljana menyebutkan bahwa tokoh Panakawan pertama kali ditampilkan oleh Empu Panuluh (abad 12) dalam karyanya Gatotkacasraya (gubahan dari Mahabarata) yang bernama Jurudyah Punta dan Prasanta.

Nama Semar mulai muncul pada masa peralihan kekuasaan majapahit ke Demak (abad 15 M). Tokoh Semar merupakan kelanjutan dari tokoh Tualen atau Naladerma atau Prasanta. Hal ini bisa menguatkan hipotesa bahwa nama Semar berasal dari bahasa Arab ismar/simaar yang berarti paku yang berfungsi sebagai pengokohan dari yang goyah, kata ini berasal dari kata sebuah hadist Islami Ismaraddunya (Islam adalah pengokohan). Tokoh semar juga telah muncul dalam candi Sukuh, ini berarti nama Semar telah ada sebelum candi sukuh didirikan. Candi sukuh dibangun pada abad XV saat kerajaan Majapahit semakin surut, semakin terpinggirkan oleh kekuatan politik dan dakwah Islam.

Pada Masa pra Islam keberadaan Panakawan digambarkan sebagai sosok abdi dan manusia biasa (kasta rendah) yang berperan sebagai pelayan dan penghibur. Peran dan posisi sebagai abdi dan penghibur ini pada masa Islam tetap dipertahankan, namun diberikan peran tambahan yang sangat 
berarti bagi dakwah Islam, dengan fungsi untuk de-sakralisasi Dewa. Semar sebagai manusia rendah justru digambarkan dan dibuatkan silsilah sebagai manusia penjelmaan dewa, atau sebagaimana manusia utusan Tuhan. Serat Purwakandha (1847) menjelaskan bahwa Semar adalah anak dari Sang Hyang Tunggal sebagaimana juga Togog. Nama Semar adalah Shang Hyang Punggung, sedangkan Togog Shang Hyang Puguh. Keberadaan Semar disejajarkan dengan Krisna (titisan Dewa Wisnu). Dalam Mahabarata versi India penasehat Pandawa adalah Krisna seorang, namun dalam kisah pewayangan penasehat Pandawa Krisna dan Semar.

Semar sebagai manusia rendah juga diberikan peran juru dakwah sebagai penasehat yang mengajarkan nilai-nilai luhur bagi umat manusia. Seno Sastramijaya berpandangan bahwa konsep Semar dan Pandawa itu melambangkan gagasaan Kawulo lan Gusti. Pandawa dapat ditinggalkan oleh Semar apabila mereka melampaui batas kebenaran. Semar juga disebut dengan julukan Semar Badranaya atau Nur Naya yang berarti cahaya tuntunan.

Sementara keberadaan tokoh Panakawan yang lain seperti Gareng, Petruk dan Bagong bisa dipastikan muncul pada pewayangan masa Islam dan belum ada pada masa sebelumnya. Adanya kelanjutan tokoh Semar dan pemuncuan tokoh tokoh yang baru (Gareng, Petruk dan Bagong) ini sejalan dengan pandangan bahwa pasa ulama pada waktu itu (Wali Songo) berkeinginan tidak menghapus wayang, namun mengubah dan menyesuaikan sehingga tidak melanggar prinsip syariat, dan dapat digunakan sebagai sarana dakwah.

Bentuk Islamisasi cerita pewayangan yang paling menonjol adalah dihilangkannya cerita tentang poliandri yang menyangkut tokoh Drupadi sebagai istri kelima bersaudara Pandawa. Kisah poliandri ini diganti menjadi cerita monogami dengan menggambarkan tokoh Drupdi sebagai Istri Yudhistira, putra tertua Pandu. Islamisasi dalam tokoh Punakawan juga dilakukan dengan menggunakan tokoh Punakawan sebagai media De-sakralisasi terhadap Dewa.
Penambahan tokoh baru dalam Punakawan dengan menggunakan bahasa yang sangat dekat dengan bahasa arab juga dilakukan untuk menambah kekuatan dakwah pada wayang, selain menambah sarana humor. Machoeld menguraikan tentang Panakawan Semar, Nala Gareng, Petruk dan Bagong, tidak dijumpai dalam epos Hindu, nama nama tersebut merupakan bahasa Arab, yaitu : Semar dari kata Ismar (paku), Nala Gareng dari kata Naala Qariin (banyak kawan), Petruk dari kata Fat-ruk (tinggalkan), dan Bagong dari kata Baghaa (berontak).

Upaya Islamisasi pada wayang juga nampak jelas pada penggambaran fisik tokoh tokoh wayang. Adanya ajaran Islam yang melarang membuat makhluk hidup menjadikan bentuk wayang menjadi semakin absurd (makin jauh) dari bentuk manusia. Fungsi dan tugas Punakawan pada masa Islam bukan sekedar abdi atau pamomong Pandawa, namun Panakawan memiliki tugas pokok sebagai penerang jalan kebenaran. Panakawan selain berperan sebagai pembantu Satria juga berperan sebagai Penasehat dan Pelindung, yang menjadi pelindung tak terbatas dalam waktu dan tempat

Dengan menggunakan teori perubahan eksternal dan internalnya Alvin Boskoff (1964), maka nampak bahwa perubahan yang terjadi pada dunia pewayangan khususnya perubahan pada tokoh Panakawan merupakan perubahan faktor eksternal. Kekuatan politik dan dakwah Islam yang menguat dan diterima semakin luas pada masyarakat Jawa, telah mendominasi dan menggeser, kekuatan dan pengaruh HinduBudha dalam dunia pewayangan. Pengaruh Islam terlihat jauh lebih besar dalam perubahan tokoh panakawan, namun pengaruh tersebut bersifat konstruktif sehingga berpengaruh pada khasanah yang makin maju dan luas terhadap wayang, khususnya tokoh Panakawan.

Perubahan karena faktor ekternal ini, nampak semakin jelas ketika diperbandingkan antara wayang di Jawa dan Bali. Pada wayang Bali tidak dikenal tokoh Semar, Petruk, Gareng, Bagong, Togog, dan Mbilung. Tokoh Panakawan pada wayang kulit Bali sangat dekat dengan yang ada dalam relief candi.. 
Bentuk Fisik tokoh Panakawan pada wayang kulit Bali lebih sesuai dengan gambaran pada relief candi. Keberadaan wayang kulit Bali yang lebih mirip dengan bentuk relief candi menunjukkan bahwa eksistensi tokoh Panakawan yang asli (sebelum Islam), masih ada namun terpinggirkan oleh dominasi pengaruh Islam.

Perubahan yang disebabkan faktor eksternal ini merupakan perubahan konstruktif. Sifat konstruktif pengaruh Islam tokoh Panakawan nampak sangat jelas dengan upaya mempertahankan banyak hal yang telah ada, dan menambah banyak hal yang baru. Sifat Konstruktif juga nampak pada masih berkembang wayang versi asli (belum dipengaruhi Islam), sebagaimana wayang Bali. Sifat konstruktif juga nampak dengan makin banyaknya cerita yang dikembangkan atau munculnya berbagai cerita carangan (cabang) dalam pewayangan.

Dianalisa dengan pandangan Koentjaraningrat tentang prinsip akulturasi budaya, maka perubahan yang terjadi pada tokoh Panakawan terjadi karena principle of function dan principle of Integration. Wayang yang semula difungsikan untuk mengajarkan kebaikan dalam kehidupan dan pengabdian terhadap dewa, oleh para ulama di fungsikan untuk hal yang hampir sama, yaitu untuk mengajarkan kebaikan dalam kehidupan dan ketaatan kepada Allah SWT.

Wayang dan Islam walaupun merupakan kebudayaan yang jauh berbeda namun dapat diintergasikan, dipadukan dan diselaraskan sehingga munculah wayang Purwa (Jawa) yang tetap melestarikan cerita lama yang telah disesuaikan dengan prinsip ajaran Islam. Ajaran Kebaikan dan Ketuhanan dalam Islam tidak bertentangan dengan ajaran lama yang telah ada pada wayang (Hindubudha).

\section{KESIMPULAN}

Dari berbagai uraian sebelumnya dapat ditarik beberapa kesimpulan antara lain

1. Tokoh Panakawan telah ada jauh sebelum Kekuatan politik dan dakwah Islam berkembang kuat di bumi Nusantara. Keberadaannya dapat terlacak dalam beberapa karya sastra yang disusun pada masa Hindu Budha seperti pada kitab Gatutkacasraya yang disusun oleh empu Panuluh pada tahun 1188M. Visualisasi keberadaan tokoh Panakawan juga nampak pada relief candi Panatara (1320 M), candi Tegowangi (1400 M) dan candi Sukuh (1437). Tokoh Panakawan juga ada dalam temuan tinggalan wayang beber yang diyakini sebagai peninggalan kerajaan Majapatit. Pada masa ini Panakawan berperanan sebagai abdi dan penghibur bagi tuannya. Panakawan digambarkan sebagai sosok manusia biasa (kasta rendah) dengan bentuk fisik yang jauh dari sempurna (namun masih proposional bentuk manusia).

2. Pada masa kekuatan politik dan dakwah Islam berkembang pesat dan diterima secara luas di Jawa, keberadaan tokoh Panakawan dalam pewayangan mengalami perubahan yang bersifat konstrukti dan terjadi secara evolutif.

3. Perbedaan tokoh Panakawan masa Pra Islam dengan masa Islam nampak jelas pada beberaa hal. (a) dari sisi jumlah tokoh terjadi penambahan jumlah yang cukup signifikan. (b) Perbedaan pada nama dan sebutan, pada masa pra islam di kenal beberapa nama yang berbeda : Pranata dan punta (serat Gatutkacasraya), Tualen dan Gagak ampuan (serat Nawaruci), Tualen, Merdah, Delem, Sangut (wayang Bali). Sementara pada masa Islam diyakini nama Panakawan berasal dari bahasa arab ; Semar, Gareng, Petruk, Bagong, Togog, dan bilung. (c) Perbedaan pada bentuk fisik, Panakawan pada masa pra Islam divisualisasikan sebagai sosok tidak idial namun masih proposional seperti manusia, sementara Panakawan pada masa Islam tetap mempertahankan gambaran sosok manusia yang tidak idial dengan bentuk yang semakin absurd sebagai bentuk manusia. (d) Perbedaan peranan dan fungsi, Panakawan masa praIslam berfungsi sebagai abdi sekaligus sebagai penghibur, pada masa Islam dilakukan penambahan fungsi sebagai penasehat, penghibur, kritikus, penyampai kebenaran, kebajikan, dan penganjur keutamaan. (e) dari sisi kejelasan asal usul, pada masa pra Islam sulit ditemukan siapa dan keturunan siapa tokoh panakawan (silsilah), sementara pada 
masa Islam keberadaan Panakawan sangat jelas silsilah keberadaannya. (f) Perbedaan pada cerita, pada masa Islam dibuat dan dimunculkan banyak cerita carangan (cabang) yang menempatkan tokoh Panakawan sebagai sentral cerita, seperti : Semar Mbangun Kayangan, Semar Boyong, Petruk dadi Ratu dan lainnya

4. Perubahan tokoh Panakawan masa Islam dan sebelumnya menunjukkan perubahan kebudayaan karena faktor eksternal, yaitu dominasi kekuatan politik dan dakwah Islam. Dalam perkembangan Panakawan, pengaruh Islam sangat terlihat jelas bukan hanyak pada penggunakaan bahasa arab dalam penamaan. Pengaruh Islam juga sangat nampak dalam upaya desakralisasi konsep Dewa dalam pewayangan. Proses de-Dewanisasi ini sangat nampak pada upaya pembuatan silsilah bahwa tokoh Panakawan juga keturunan dewa, yang memiliki kekuatan, kearifan, kebijaksanaan yang digambarkan melebihi dari Dewa-Dewa yang diagungkan dalam Hindu-Budha.

\section{DAFTAR PUSTAKA}

Alvin Boskoff, 1964, "Recent Theories of Social Change", dalam Sosiology and History, Werner J Cahnman dan Alvin Boskoff (eds). London: The Free Press of Glencoe

Agus Sunyoto, Atlas Walisongo, (Yogyakarta : Mizan, 2012)

Ardian Kresna, Punakawan Simbol Kerendahan Hati Orang Jawa (Yogyakarta: Narasi, 2012)

------------, Mengenal Wayang (Yogyakarta: Laksana, 2012)

Budiono Kusumohamidjojo, Filsafat Kebudayaan Proses Realisasi Manusia (Yogyakarta: Jalasutra, 2009)

Deny Hermawan, Semar dan Kentut Kesayangannya (Yogjakarta: Diva Press, 2013)

Harsojo, Pengantar Antropologi (Bandung : Binacipta, 1988)

Haryanto, S. Bayang-bayang Adhiluhung: Filfasat, Simbolis, dan Mistik Dalam Wayang (Semarang: Dahara Prize, 1985)

Hazeu, G.A.J., Bijdrage tot de Kennis van het Javaansche Toneel, (Leiden:E.J,. Brill, 1897).
I.G.B.N. Panji, Ensikopedia Mini Pewayangan Bali (Denpasar: Yayasan Pewayangan Daerah Bali, 1987),

I Gusti Bagus Arthanegara, Wayang Kulit Koleksi Musium Bali (Denpasar: Proyek Pengembangan Media Kebudayaan, Dirjen Kebudayaan Departemen Pendidikan dan Kebudayaan, 1977),

Ki Padmopuspita Y., Candi Sukuh dan Kidung Sudamala (Jakarta: Proyek Pengembangan Media Kebudayaan, Dirjen, Kebudayaan Departemen Pendidikan dan Kebudayaan, 1976),

Mangkudimedjo, R.M., Hazeu, G.A.J., Sumarsono, Hardjono H.P., Kawruh Asalipun Ringgit Purwa Sarta Gegepokanipun Kaliyan Agami Ing Jaman Kina, (Jakarta: Departemen Pendidikan dan Kebudayaan Proyek Penerbitan Buku Bacaan dan Sastra Indonesia dan Daerah, 1979)

Nurhadi Siswanto., Perubahan Pandangan ontologi Panakawan masa Pra Islam dan masa Islam, Wisdom Jurnal Filsafat, https://jurnal.ugm.ac.id/wisdom/article/vi ew/22093

Poedjosoebroto, R., Wayang : Lambang Ajaran Islam (Jakarta : Pradnya Paramita, 1878)

R. Poedjosoebroto, Wayang Lambang Ajaran Islam (Jakarta: Pradnya Paramitra, 1978)

Soetarno dan Sarwanto, Wayang Kulit dan Perkembangannya (Solo: ISI Press, 2010)

Sri Mulyono, Wayang, Asal-usul, Filsafat, dan Masa Depannya, (Jakarta: Gunung Agung, 1975)

------------,Simbolisme dan Mistikisme dalam Wayang (Jakarta: Gunung Mas, 1974)

Sunarto, Wayang Kulit Purwa dalam Pandangan Sosial Budaya (Yogyakarta: Arindo Nusa Media, 2009)

---------, Panakawan Yogyakarta (Yogyakarta : BP ISI Yogyakarta, 2012)

Zarkasi, Effendi. Unsur-Unsur Islam Dalam Pewayangan Telaah Terhadap Penghargaan Walisanga terhadap Wayang Untuk Media dakwah Islam. (Solo: Yayasan Mardikintoko,1996) 